\title{
Corrupção na educação superior pública? Estudo das Ifes de Minas Gerais
}

Jamile Camargos de Oliveira ${ }^{1}$

Marcus Vinicius Gonçalves da Cruz 1

1 Fundação João Pinheiro / Programa de Mestrado em Administração Pública, Belo Horizonte / MG - Brasil

\begin{abstract}
A corrupção na administração pública brasileira vem adquirindo maior centralidade graças aos sucessivos escândalos desvendados no país. As instituições públicas federais de ensino superior (Ifes) não passaram incólumes por esse contexto, chamando a atenção por se tratar de organizações voltadas à promoção da formação intelectual e cidadã. Este artigo analisa de que forma o ambiente organizacional se configura para o combate à corrupção por meio de um estudo de caso nas 17 Ifes de Minas Gerais. Para isso, verificam-se as características relacionadas com a corrupção em processos disciplinares administrativos (PADs), instaurados de 2015 a 2019, e entrevistam-se servidores que participavam da condução desses processos. A despeito de a maioria dos entrevistados não ter uma percepção clara do fenômeno da corrupção nas Ifes, os achados da pesquisa indicam que os principais fatores do ambiente organizacional referentes à integridade que contribuem para o combate à corrupção correspondem aos canais para manifestação de denúncia, aos mecanismos de controle externo e interno, aos instrumentos de promoção da ética e às regras de conduta, transparência e acesso à informação. Em termos de estrutura, constata-se que o corporativismo é o principal empecilho do ambiente organizacional no combate à corrupção. Para isso, sugere-se o desenvolvimento de pesquisas futuras voltadas a verificar a institucionalização das medidas da integridade nas Ifes como estratégia de combate à corrupção.

Palavras-chave: corrupção; integridade; ifes; universidade; corporativismo.
\end{abstract}

\section{¿Corrupción en la educación superior pública? Estudio de las Ifes de Minas Gerais}

La corrupción en la administración pública brasileña ha ido adquiriendo mayor centralidad debido a los sucesivos escándalos develados en el país. Las instituciones públicas federales de educación superior (Ifes) no permanecieron indemnes a este contexto, llamando la atención por tratarse de organizaciones orientadas a promover la educación intelectual y ciudadana. Este artículo analizó cómo se configura el entorno organizacional para combatir la corrupción a través de un estudio de caso en las 17 Ifes de Minas Gerais. Para ello, se verificaron las características relacionadas con la corrupción en los procesos administrativos disciplinarios (PAD) instaurados de 2015 a 2019 y se entrevistó a los funcionarios que participaron en la conducción de estos procesos. A pesar de que la mayoría de los entrevistados no tuviera una percepción clara del fenómeno de la corrupción en las Ifes, los hallazgos de la investigación indicaron que los principales factores del entorno organizacional relacionados con la integridad que contribuyen a la lucha contra la corrupción corresponden a los canales para la manifestación de denuncias, mecanismos de control externo e interno, instrumentos de promoción de la ética y reglas de conducta, transparencia y acceso a la información. En términos de estructura, se encontró que el corporativismo era el principal obstáculo del entorno organizacional en la lucha contra la corrupción. Se sugiere desarrollar investigaciones futuras orientadas a verificar la institucionalización de las medidas de integridad en las Ifes como estrategia de combate a la corrupción. Palabras clave: corrupción; integridad; Ifes; universidad; corporativismo. 


\section{Is there corruption in public higher education institutions? Study of the HEls of Minas Gerais}

Corruption in the Brazilian public administration has gained centrality due to the successive scandals unveiled in the country. The public higher education institutions (HEIs) did not go unscathed, bringing attention to the fact that they are organizations aimed at promoting citizenship and intellectual education. This article analyzed how the organizational environment is configured to fight corruption through a case study of the 17 HEIs in Minas Gerais. We verified characteristics related to corruption in administrative disciplinary proceedings established between 2015 and 2019 and interviewed civil servants who participated in the conduction of these processes. Although most interviewees did not have a clear perception of corruption in the HEIs, the research findings indicated the main factors related to integrity that contribute to fighting corruption in the organizational environment. These factors are the complaints channels, external and internal control mechanisms, instruments for promoting ethics and rules of conduct, transparency, and access to information. In terms of structure, it was found that corporatism was the main obstacle to fight corruption in the organizational environment. The study points out the need for future research to verify the institutionalization of integrity measures in the HEIs as a strategy to combat corruption. Keywords: corruption; integrity; public HEIs; university; corporatism.

\section{AGRADECIMENTOS}

Os autores agradecem à CAPES, CNPq e FAPEMIG pelo auxílio à pesquisa.

\section{INTRODUÇÃO}

A corrupção na administração pública vem sendo destaque nos últimos anos no Brasil e adquirindo maior centralidade graças aos sucessivos escândalos desvendados no país (Pinho \& Sacramento, 2018; Sadek, 2019). A corrupção não é um elemento novo na vida brasileira (Romeiro, 2015; Schwarcz, 2008), e seu caráter multifacetado e complexo já é conhecido (Fortini \& Shermam, 2018; Rose-Ackerman \& Palifka, 2016), mas investigações recentes tiveram elevado impacto midiático e culminaram na condenação de vários políticos e empresários brasileiros, como o Escândalo do Mensalão (Sadek, 2019) e a Operação Lava-Jato (Bechara \& Goldsmith, 2020; Gonçalves \& Andrade, 2019; Marcelino \& Oliveira, 2021), reverberando consequências políticas e culturais (Mendonça \& Figueiredo, 2019; Odilla, 2020).

As dinâmicas relacionadas com a corrupção também envolveram denúncias ligadas à educação superior, como circunstâncias referentes à obtenção fraudulenta de vagas ou diplomas, privilégios a determinados alunos, comportamento eticamente ambíguos no desenvolvimento de pesquisas, plágio de publicações científicas, em geral obnubiladas pelo relevante papel social e moral que desempenha (Faria, 2015; Osipian, 2008). No caso brasileiro não foi diferente, como as irregularidades detectadas em contratos firmados pela Universidade de Brasília (UnB) por dispensa de licitação em 2008 (Fraga \& Motta, 2013), a investigação por desvio de valores em bolsas de pesquisas da Universidade Federal do Paraná (UFPR) em 2013 (Leher, 2019) ou a apuração de denúncias na Universidade Federal de Santa Catarina (UFSC) que culminaram no trágico suicídio do reitor, em 2017 (Oliveira, 2019).

A prevenção e o combate à corrupção se revestem de distintas medidas, como a consolidação da legislação (Godinho, 2011; Oliveira \& Neves, 2014), o incremento do controle social e da transparência (Bataglia \& Farranha, 2020; Rose-Ackerman \& Palifka, 2016), a diminuição de desigualdades (Machado \& Paschoal, 2016; Pinto, 2011) e a consolidação de sistema de integridade (Fortini \& Shermam, 2017; Independent Commission Against Corruption [Icac], 2018; Viol, 2021). Entretanto, de acordo com a 
Organização para a Cooperação e o Desenvolvimento Econômico (OCDE, 2020, p. 5), a integridade pública é uma das respostas estratégicas e sustentável à corrupção, pois as "abordagens tradicionais baseadas na criação de mais regras, conformidade mais rigorosa e cumprimento mais rígido têm eficácia limitada”.

Desde 2010, foram promulgadas diversas normativas aplicadas ao serviço público brasileiro, abrangendo também as instituições públicas federais de ensino superior (Ifes), no intuito de coibir a corrupção e promover a integridade corporativa e pública, como o Decreto no 7.203 (Decreto $\mathrm{n}^{\circ}$ 7.203, de 04 de junho de 2010), que veda a prática de nepotismo; a Lei de Acesso à Informação (LAI) (Lei $\mathrm{n}^{\circ}$ 12.527, de 18 de novembro de 2011); o Decreto $\mathrm{n}^{\circ} 7.724$ (Decreto $\mathrm{n}^{\circ} 7.724$, de 16 de maio de 2012), que regulamenta o acesso à informação; a Lei de Conflito de Interesses (Lei no 12.813, de 16 de maio de 2013); e o Decreto da Governança (Decreto n 9.203, de 22 de novembro de 2017).

Desse modo, o artigo tem como objetivo analisar de que forma o ambiente organizacional se configura no combate à corrupção em Ifes, órgãos vinculados à estrutura do Ministério da Educação (MEC) e responsáveis pela transmissão e pela geração de conhecimento (ensino e pesquisa), bem como pela transferência de benefícios à sociedade (extensão) à luz da integridade. As Ifes são dependentes do repasse orçamentário federal para custear suas despesas com pessoal, custeio e capital (Lei n ${ }^{\circ}$ 9.394, de 20 de dezembro de 1996). Desse modo, a autonomia orçamentária e de gestão financeira está sujeita às orientações e aos critérios dos poderes político e econômico. Todavia, a educação pública superior é vista no Brasil como um custo, e não como um investimento, sendo constantes contingenciamento e cortes de recursos (Caetano \& Campos, 2019).

Assim, não obstante as dificuldades provocadas pela dispersão do poder (Vieira \& Vieira, 2004); pelas fragilidades dos gestores universitários (Tosta, Dalmau, Tosta \& Tecchio, 2012); pelos empecilhos para gerir as relações administrativas, de subordinados e pessoais (Santos \& Bronnemann, 2013); pela redução da autonomia e do orçamento (Caetano \& Campos, 2019); e pela sobrecarga de tarefas dos servidores efetivos (Pires \& Oliveira, 2020), as Ifes têm de se adequar também às exigências legais e às normas das entidades reguladoras (Santos \& Bronnemann, 2013).

Os servidores públicos das Ifes são regidos pelo Código de Ética Profissional do Servidor Público Civil, do Poder Executivo Federal, que dispõe sobre os princípios morais e éticos a serem observados. No entanto, de 2003 a 2020, foram aplicadas pelos órgãos e pelas entidades do Poder Executivo Federal a servidores públicos federais civis pertencentes ao Ministério da Educação - que, em sua maioria, estão lotados nas Ifes - 1.599 sanções expulsivas, sendo que $23,83 \%$ foram expulsos por terem cometido atos corruptos, havendo um aumento do número de expulsões: de 85, em 2010, para 171, em 2019 (Controladoria-Geral da União [CGU], 2020). Assim, para alcançar o objetivo deste estudo, analisaram-se os processos administrativos disciplinares (PADs) instaurados de 2015 a 2019 nas Ifes de Minas Gerais e entrevistaram-se servidores que participavam da condução desses processos.

Do ponto de vista teórico, permanece pouco explorada na literatura nacional a forma como o fenômeno da corrupção se materializa no contexto da educação superior no país, com a pesquisa propiciando a divulgação de informações ao meio acadêmico que permitem compreender, prevenir e combater a corrupção (Barreto, Midlej \& Gomes, 2019; Marani, Brito, Souza \& Brito, 2018). Em termos sociais, os danos provocados pela corrupção não se limitam ao órgão que foi diretamente lesado, e os prejuízos não são somente econômicos, pois ela também afeta negativamente a esfera política $\mathrm{e}$ social (Ang, 2020; OCDE, 2020; Sadek, 2019). Ademais, do ponto de vista prático, os resultados deste estudo podem contribuir para a instrumentalização de estratégias de prevenção e enfrentamento à 
corrupção no âmbito das Ifes, tendo em vista que uma análise realizada pelo Tribunal de Contas da União (TCU, 2018) quanto à exposição ao risco de ocorrência de casos de fraude e corrupção indicou que, das 17 Ifes objetos do estudo, apenas 1 apresentava baixa exposição ao risco de fraude e corrupção.

O texto se estrutura em 5 seções, incluindo a Introdução e a Considerações Finais. Na segunda parte, apresenta-se uma literatura sobre o fenômeno da corrupção, articulando-a à integridade. $\mathrm{Na}$ terceira, abordam-se dados e métodos, explorando os procedimentos de pesquisa. Na quarta, analisa-se o conteúdo dos PADs e como os entrevistados reconhecem a dimensão do fenômeno da corrupção nas Ifes estudadas.

\section{REFERÊNCIAS TEÓRICAS SOBRE CORRUPÇÃO E INTEGRIDADE}

A corrupção está presente na sociedade brasileira desde sua colonização, apresentando uma variação histórica de padrões, conforme o desenvolvimento econômico e democrático do país, como indicam diversos estudos nessa seara (Balbe, 2006; Filgueiras, 2008; Romeiro, 2015; Schwarcz, 2008). Todavia, distintas estratégias foram adotadas no intuito de combater essa mazela, como a modernização do Estado desde a Era Vargas (Bresser-Pereira, 2006; Filgueiras \& Aranha, 2011); a promulgação da Constituição Federal de 1988, considerada o grande marco normativo de combate à corrupção do país; e a criação e o fortalecimento de instituições de controle (Filgueiras \& Aranha, 2011; Machado \& Paschoal, 2016; Viol, 2021).

Pinho e Sacramento (2018, p. 205), no entanto, são enfáticos ao afirmarem que "a corrupção no Brasil tem avançado aceleradamente nas últimas décadas, apesar da implantação de instituições e leis de combate ao fenômeno; não se vislumbra, pelo menos no médio prazo, possibilidade concreta de rompimento desse círculo vicioso". Dessa forma, a despeito das diversas mudanças ocorridas na administração pública ao longo dos tempos, a corrupção ainda é uma mazela recorrente no país.

Outro desafio é a própria definição de corrupção, dadas a complexidade e a pluridimensionalidade do tema. Essas definições não são estáticas e podem evoluir conforme o entendimento daquilo que a sociedade considera corrupto (Brei, 1996; Filgueiras, 2008; Miranda, 2018).

A Transparência Internacional (2020) adota uma definição sucinta e abrangente: é o abuso de poder confiado a alguém para obtenção de ganho privado. Rose-Ackerman (2005), por sua vez, acrescenta os ganhos políticos. Na visão de Barreto, Midlej e Gomes (2019, p. 2), a corrupção é um fenômeno que se refere ao "uso de cargos públicos para ganhos privados, em que um agente público se encarrega de realizar algum tipo de tarefa utilizando de má-fé para enriquecimento privado". Todavia, Sadek (2019, p. 1278) adverte que as percepções sobre a corrupção "devem ser analisadas com o devido cuidado, uma vez que não se confundem com a realidade nem resultam de análises baseadas em rigor científico", indicando um conceito multifacetado.

Ainda que não haja consenso sobre a definição da corrupção, há diferentes interpretações sobre as práticas consideradas corruptas (Marcelino \& Oliveira, 2021). Rose-Ackerman (2005) reforça que suborno, fraude, peculato e conflitos de interesse são considerados ilegais na maioria dos países, mas não é unanimidade. Para Rothstein (2018, p. 37), a corrupção assume muitas formas, "de demandas diretas por altos subornos em intercâmbio por cuidados de saúde para intercâmbios mais sutis de favores pessoais em relação ao recrutamento ou à promoção de funcionários públicos". Já os modelos clássicos, por exemplo, se concentram na prática de suborno (Ang, 2020).

Para Miranda (2018, p. 256), só há corrupção quando há trocas, por isso ele a define como o "pagamento ilegal (financeiro ou não) para a obtenção, a aceleração ou para que haja ausência de um 
serviço feito por um funcionário público ou privado". Em sua perspectiva, podem ser identificadas a "pequena corrupção", que se refere aos atos praticados pelos burocratas de nível de rua, como o pequeno suborno e roubo; a "grande corrupção", que está relacionada com as preferências das elites políticas e afeta a eficácia das políticas em desenvolvimento; e a "corrupção legislativa", que é a forma como o voto dos legisladores é influenciado por um grupo de interesse.

Assim, do mesmo modo que existem diversas perspectivas sobre o que é corrupção, há também várias abordagens sobre como combater essa mazela, sendo a integridade uma das respostas estratégicas e sustentável. Na óptica da Transparência Internacional (2000), a integridade compreende um sistema de freios e contrapesos projetado para alcançar a responsabilização entre unidades do governo, por meio de accountability, transparência, prevenção e penalidade. Por sua vez, Castro, Amaral e Guerreiro (2019, p. 190) frisam a relação entre a integridade e a corrupção, ao definirem integridade como um "conjunto de mecanismos e procedimentos internos para a aplicação efetiva de diretrizes que detectem e mitiguem desvios, fraudes, irregularidades e atos ilícitos praticados contra a administração pública”, reforçando a integridade como estratégia de prevenção e combate à corrupção.

Nos anos 2000, a discussão sobre a integridade aumentou significantemente graças à pressão dos organismos multilaterais, como a Organização das Nações Unidas (ONU), o Banco Mundial e a OCDE (Vieira \& Barreto, 2019). Esses órgãos passaram a considerar a questão da integridade essencial para o progresso político e econômico, sendo responsáveis por iniciativas e convenções, regras, diretrizes de monitoramento e sanções (Huberts \& Graaf, 2014; Machado \& Paschoal, 2016). Para Cochrane (2020), a demanda sobre o setor público para atender aos mais altos padrões de integridade aumentou significativamente em razão das evidências de declínio da confiança pública nas instituições governamentais.

No que tange a leis e normativos que visavam coibir a corrupção e promover a integridade corporativa e pública, o Brasil buscou aperfeiçoar seu aparato normativo ao longo do tempo, com nova ênfase a partir dos anos 2000. Vieira e Barreto (2019) ressaltam que, com a aprovação da Lei Anticorrupção (Lei $\mathrm{n}^{\circ} 12.846$, de 01 de agosto de 2013), houve um interesse em torno dos programas de integridade, ampliada após o Decreto da Governança (Decreto n 9.203, de 22 de novembro de 2017), que tornou obrigatória a órgãos e entidades da administração direta, autárquica e fundacional a instituição de programas de integridade. Nesse contexto de disseminação desses programas, coube à Controladoria-Geral da União (CGU) a responsabilidade de operacionalizar as medidas de integridade (Viol, 2021).

Essas ações consistem na constituição de unidade de integridade e na elaboração e aprovação de um plano de integridade contendo as seguintes medidas institucionais: promoção da ética e de regras de conduta para servidores, fomento da transparência ativa e do acesso à informação, tratamento de conflitos de interesses e nepotismo, prática de denúncias, verificação do funcionamento de controles internos e do cumprimento de recomendações de auditoria, além de implementação de procedimentos de responsabilização. Estipulou-se que a CGU seria a responsável por monitorar o atendimento das instituições ao disposto na Portaria CGU no 57 (Portaria CGU no 57, de 04 de janeiro de 2019). Em termos gerais, o arcabouço proposto pela CGU busca delinear uma possível institucionalização de parâmetros de governança voltados à integridade.

Em suma, a integridade é uma combinação de estratégias baseadas primordialmente na prevenção e na promoção da ética e de regras de conduta com aquelas focadas na correição, com o intuito de mitigar e combater irregularidades, atos ilícitos e práticas corruptas, retrato do fenômeno da corrupção (Cochrane, 2020). 
Diante do apresentado, o conceito de corrupção é multifacetado. Por isso, para a análise de resultados deste artigo, define-se "corrupção" como um conjunto de práticas que sobrepõem os interesses privados aos públicos, a fim de obter vantagens (pecuniárias e/ou políticas) ilegais para si ou para outrem, por meio de trocas entre atores ou pela adoção de um comportamento desviante.

\section{MATERIAL E MÉTODOS}

No intuito de analisar os fatores do ambiente organizacional que contribuem para o combate à corrupção nas Ifes, realizou-se uma pesquisa qualitativa (Denzin \& Lincoln, 2000), de cunho descritivo (Collis \& Hussey, 2005), por meio de um estudo de caso múltiplo (Yin, 2001).

No que se refere à coleta de dados, utilizaram-se fontes diversas de evidências, como recomendado por Eisenhardt (1989): consultas bibliográficas sobre os assuntos de corrupção, integridade e Ifes; análise documental; e pesquisa de campo por meio de entrevistas semiestruturadas.

Realizou-se a análise documental nos moldes de Silva, Emmendoerfer e Cunha (2020), valendo-se de exames de conteúdo de PADs e partindo do pressuposto de que eles podem ser um dos canais visíveis dos possíveis desvios que ocorrem nessas organizações, uma vez que, para que um servidor seja expulso, a administração deve fazer uso do seu poder disciplinar, a fim de apurar a infração cometida, por meio da instauração do PAD (Gomes, 2014). Os PADs são um instrumento obrigatório que devem ser instaurados mediante a ciência da irregularidade no serviço público, visando apurar as infrações funcionais e aplicar penalidades de suspensão por mais de 30 dias; de demissão, cassação de aposentadoria ou disponibilidade; ou de destituição de cargo em comissão (Lei no 8.112, de 11 de dezembro de 1990). Eles são classificados de acordo com os tipos de irregularidade investigada, sendo denominada de assunto pela CGU.

O Quadro 1 apresenta os 26 assuntos dos PADs instaurados para apurar irregularidades cometidas por servidores públicos civis do Poder Executivo Federal, de acordo com o Painel Correição em Dados da CGU. Selecionaram-se 8 desses 26 assuntos que poderiam estar relacionados com o fenômeno da corrupção: acumulação indevida de cargos; descumprimento de regime de dedicação exclusiva; concessão irregular de benefícios, licenças ou autorizações; conflito de interesse entre a função pública e atos da vida privada; desaparecimento ou perecimento de bens públicos; favorecimento próprio ou de terceiros e outros; irregularidades ou fraudes em convênios ou outros acordos; e irregularidades ou fraudes em licitações ou contratos. Essa seleção foi feita de acordo com a análise semântica dos assuntos (Bardin, 2016) e, posteriormente, corroborada pela percepção dos entrevistados.

Como o PAD é sigiloso para acesso de terceiros durante todo o seu curso, passando a ser acessível assim que concluído (Lei no 12.527 , de 18 de novembro de 2011), solicitou-se, via sistema eletrônico do Serviço de Informação ao Cidadão (e-Sic), acesso aos 92 PADs instaurados e concluídos de 2015 a 2019, nas 17 Ifes de Minas Gerais, sobre os 8 assuntos selecionados.

Analisou-se esse recorte temporal tendo em vista que um levantamento realizado em setembro de 2020, no Painel Correição em Dados, demonstrou um aumento, a partir de 2015, do número de sanções expulsivas no MEC (CGU, 2020). Assim, partindo do pressuposto de que a maioria dos servidores do referido ministério está lotada nas Ifes e que frequentemente as sanções expulsivas aplicadas aos servidores federais estão relacionadas com casos de corrupção, investigou-se esse período a fim de visualizar as possíveis dinâmicas desse fenômeno. 


\section{QUADRO 1 ASSUNTOS PARA INSTAURAÇÃO DOS PADS}

\begin{tabular}{|c|c|}
\hline Ordem & Assuntos \\
\hline 1 & Acumulação indevida de cargos \\
\hline 2 & Assédio moral \\
\hline 3 & Assédio sexual \\
\hline 4 & Ausência de presteza nas atividades ou na prestação de informações \\
\hline 5 & Ausência ou impontualidade ao serviço \\
\hline 6 & BDE (a classificar) \\
\hline 7 & Concessão irregular de benefícios, licenças ou autorizações \\
\hline 8 & Conflito de interesse entre função pública e atos da vida privada \\
\hline 9 & Desaparecimento ou perecimento de bens públicos \\
\hline 10 & Descumprimento da Lei de Acesso à Informação \\
\hline 11 & Descumprimento de normas relacionadas ao orçamento público \\
\hline 12 & Descumprimento de regime de dedicação exclusiva \\
\hline 13 & Designação de atribuições a pessoa estranha à repartição \\
\hline 14 & Desproporção entre patrimônio e renda \\
\hline 15 & Desrespeito ao sigilo de informações \\
\hline 16 & e-OUV (a classificar) \\
\hline 17 & Erros procedimentais ou descumprimento de normas ou regulamentos \\
\hline 18 & Falta de urbanidade, conduta escandalosa, incontinência pública e manifestação de apreço ou desapreço \\
\hline 19 & Favorecimento próprio ou de terceiros e outros \\
\hline 20 & Irregularidades definidas em normativos ou regulamentos \\
\hline 21 & Irregularidades ou fraudes em convênios ou outros acordos \\
\hline 22 & Irregularidades ou fraudes em licitações ou contratos \\
\hline 23 & Monitor (a classificar) \\
\hline 24 & Nepotismo \\
\hline 25 & Reconhecimento de dívida \\
\hline 26 & Representação de interesse particular junto à administração \\
\hline
\end{tabular}

Fonte: CGU (2020). 
Algumas Ifes, contudo, indeferiram o pedido de acesso ao conteúdo completo dos PADs. Alguns dos motivos alegados para isso foram: não ter os processos em meio eletrônico, insuficiência de servidores e equipamentos para digitalizar documentos, dificuldades para ocultar os dados sigilosos etc. Assim, decidiu-se simplificar o pedido de acesso e solicitou-se parte dos PADs: relatório final elaborado pela comissão, parecer da procuradoria jurídica e decisão da autoridade competente.

Este estudo realizou entrevistas semiestruturadas com servidores diretamente envolvidos na condução dos PADs, partindo da ideia de que o responsável por registrar as irregularidades poderia visualizar as dinâmicas da corrupção. As entrevistas foram realizadas com base em amostra não probabilística, intencionalmente selecionada de acordo com os interesses da pesquisa (amostragem intencional) (Thiry-Cherques, 2009).

Desse modo, entrevistaram-se por meio remoto, entre outubro e novembro de 2020, o interlocutor qualificado e 10 servidores das Ifes. A primeira entrevista foi realizada com o interlocutor qualificado, selecionado em razão de seu notório saber, visto que ocupava a função havia mais de 5 anos, no intuito de verificar se o roteiro de entrevista estava adequado. A partir da sétima entrevista, nenhuma informação nova foi registrada, indicando que o critério de levantamento foi adequado (Salmons, 2014).

O ético sigilo da fonte foi preservado, conforme recomendado pela Resolução $\mathrm{n}^{\circ} 510$, de 07 de abril de 2016, do Conselho Nacional de Saúde, por isso a descrição dos informantes foi feita no masculino, não obstante o sexo, e a diferenciação deles se deu por meio de nomes genéricos, sem correspondência direta com a identificação das Ifes, para as quais foram também adotados nomes genéricos, atribuídos aleatoriamente (Ifes 1 a 17), tendo em vista que esta pesquisa não visa comparar uma instituição com a outra, e sim analisar como o ambiente organizacional se configura no combate à corrupção nas Ifes.

Em relação à análise de dados, procedeu-se a um exame de conteúdo para os dados primários e secundários, nos moldes descritos por Bardin (2016), que considera 3 etapas distintas: pré-análise, descrição analítica e interpretação referencial. A primeira consiste na organização propriamente dita e está sintetizada no Quadro 2. Das 17 Ifes que foram objeto deste estudo, apenas a Ifes 15 não forneceu acesso aos dados nem respondeu aos convites para as entrevistas.

Com a constituição de um corpus, realizou-se a segunda etapa (descrição analítica), por meio da definição de categorias. A análise de conteúdo dos PADs foi feita com base em 2 categorias: corrupção e integridade. Na categoria "corrupção", no intuito de verificar se as irregularidades que motivaram a abertura do PAD estavam relacionadas com o fenômeno da corrupção, analisaram-se atos corruptos a partir daqueles considerados corrupção pela CGU. O órgão considera corrupção os atos previstos nos artigos 43, incisos LXI e IX, da Lei no 4.878 (Lei no 4.878, de 03 de dezembro de 1965); e nos artigos 117, incisos IX, XII, XII e XVI, da Lei no 8.112 (Lei no 8.112, de 11 de dezembro de 1990), e 132, incisos IV, X e XI da referida lei. Como a Lei no 4.878 (Lei no 4.878, de 03 de dezembro de 1965) é referente ao regime jurídico peculiar dos policiais, que não foi objeto deste estudo, foi considerado ato corrupto, para a análise dos PADs, o conteúdo dos incisos referentes à Lei no 8.112 (Lei no 8.112, de 11 de dezembro de 1990). 


\section{QUADRO 2 CARACTERIZAÇÃO DA ANÁLISE DOS DADOS COLETADOS}

\begin{tabular}{|c|c|c|c|c|c|}
\hline Instituição & PADs analisados & Cargo do entrevistado & Tempo de serviço & $\begin{array}{l}\text { Tempo na atual } \\
\text { função }\end{array}$ & $\begin{array}{c}\text { Duração da } \\
\text { entrevista }\end{array}$ \\
\hline $\begin{array}{l}\text { Interlocutor } \\
\text { Qualificado }\end{array}$ & - & Docente & 47 anos & 7 anos & 45 minutos \\
\hline Ifes 1 & Não fornecido & Técnico-administrativo & 32 anos & 6 anos & 65 minutos \\
\hline Ifes 2 & 2 & \multicolumn{4}{|c|}{ Não respondeu ao convite } \\
\hline Ifes 3 & 8 & Técnico-administrativo & 9 anos & 2 anos & 40 minutos \\
\hline Ifes 4 & 1 & Docente & 4 anos & 8 meses & 65 minutos \\
\hline Ifes 5 & 3 & Técnico-administrativo & 8 anos & 4 anos & 43 minutos \\
\hline Ifes 6 & 1 & Técnico-administrativo & 10 anos & 8 anos & 65 minutos \\
\hline Ifes 7 & 5 & Docente & 18 anos & 3 anos & 80 minutos \\
\hline Ifes 8 & 0 & Técnico-administrativo & 7 anos & 3 anos & 75 minutos \\
\hline Ifes 9 & 8 & \multicolumn{4}{|c|}{ Não respondeu ao convite } \\
\hline Ifes 10 & 5 & \multicolumn{4}{|c|}{ Não respondeu ao convite } \\
\hline Ifes 11 & 3 & Técnico-administrativo & 3 anos & 3 anos & 90 minutos \\
\hline Ifes 12 & 3 & Técnico-administrativo & Não informado & 5 anos & 70 minutos \\
\hline Ifes 13 & Não fornecido & Técnico-administrativo & 27 anos & 17 anos & 105 minutos \\
\hline Ifes 14 & 7 & \multicolumn{4}{|c|}{ Não tinha interesse em conceder a entrevista } \\
\hline Ifes 15 & Não fornecido & \multicolumn{4}{|c|}{ Não respondeu ao convite } \\
\hline Ifes 16 & 1 & \multicolumn{4}{|c|}{ Não respondeu ao convite } \\
\hline Ifes 17 & 2 & \multicolumn{4}{|c|}{ Não respondeu ao convite } \\
\hline
\end{tabular}

Fonte: Elaborado pelos autores.

$\mathrm{Na}$ categoria "integridade", visando analisar os fatores do ambiente organizacional que contribuem para combater a corrupção nas Ifes, verificaram-se algumas das medidas institucionais da integridade descritas pela Portaria CGU no 57 (Portaria CGU nº 57, de 04 de janeiro de 2019) e usadas para detectar a irregularidade investigada no PAD.

Já a análise de conteúdo das entrevistas foi feita com base em 3 categorias: corrupção, integridade e estrutura. Na categoria "corrupção", verificou-se a existência de corrupção na Ifes pela percepção do entrevistado. Na categoria "integridade", analisaram-se medidas institucionais da integridade descritas pela Portaria CGU no 57 (Portaria CGU no 57, de 04 de janeiro de 2019), que visam combater a corrupção, e os canais mais usados de detecção das irregularidades. Para a categoria "estrutura", apuraram-se as dificuldades para a prevenção e o combate à corrupção.

$\mathrm{Na}$ terceira fase, que consiste no tratamento dos resultados brutos no intuito de torná-los significativos e válidos, realizaram-se inferências e interpretações baseadas em combinação dos 
resultados obtidos e do embasamento teórico (Bardin, 2016), visando identificar os fatores do ambiente organizacional que se configuram para o combate à corrupção nas Ifes.

\section{APRESENTAÇÃO E ANÁLISE DE RESULTADOS}

Durante a fase de pré-análise da pesquisa documental dos PADs, verificou-se que, dos 72 disponibilizados, 49 estavam no escopo da pesquisa. Portanto, procedeu-se ao tratamento dos resultados desses 49 processos. Em relação às entrevistas, os resultados apresentados se referem às percepções dos 10 entrevistados e do interlocutor qualificado, totalizando 11 entrevistas. É oportuno registrar que alguns resultados foram apresentados na forma de frequência, no intuito de ilustrar e comparar os dados obtidos, sem nenhuma pretensão de fornecer uma análise estatística.

Em relação à categoria "corrupção", apurou-se que, dos 49 PADs analisados, em somente 6 houve uma ação corrupta com base nos atos considerados corrupção pela CGU, cuja penalidade prevista é a demissão. Quatro foram demitidos conforme previsto no inciso IV, art. 132, da Lei no 8.112 (Lei $\mathrm{n}^{\circ}$ 8.112, de 11 de dezembro de 1990), que versa sobre a improbidade administrativa. Outra demissão ocorreu em razão da previsão do inciso $\mathrm{X}$, do referido artigo: lesão aos cofres públicos e dilapidação do patrimônio nacional. Por fim, a ação do outro servidor demitido foi enquadrada ao mesmo tempo como improbidade administrativa (inciso IV) e corrupção (inciso XI).

Já a pesquisa de campo demonstrou que 8 dos 11 entrevistados consideraram que há corrupção nas Ifes, ainda que metade desses 8 entenda que os casos são raros (entrevistados 4, 5, 7 e 8). No entanto, se os casos investigados nos PADs e relatados pelos entrevistados fossem analisados sob o prisma de corrupção adotado neste artigo - conjunto de práticas que sobrepõem os interesses privados aos públicos, no intuito de obter vantagens ilegais para si ou para outrem, por meio de trocas entre atores ou pela adoção de um comportamento desviante -, haveria a possiblidade de ampliar o leque de interpretação dos eventos de corrupção ocorridos nas Ifes. Por exemplo, o Interlocutor Qualificado cita que, na Ifes em que trabalha, há muitos casos de descumprimento de dedicação exclusiva, porém ele não considera essas ações atos corruptos. Tal perspectiva pode ser corroborada pela análise documental, uma vez que, dos 8 PADs analisados da Ifes 3, 2 estavam relacionados com o descumprimento de dedicação exclusiva e não foram considerados corrupção, apesar de ter sido comprovada a irregularidade.

O servidor, ao adotar um regime de trabalho de dedicação exclusiva, tem ciência de que receberá um adicional ao salário que o impede de exercer outra atividade remunerada, exceto as permitidas em lei. Dessa forma, ao descumprir esse regime, há o enriquecimento ilícito, que, de acordo com o conceito adotado neste artigo, seria um ato corrupto, pois há a sobreposição dos interesses privados aos públicos, com o objetivo de obter vantagens ilegais para si.

Desse modo, observa-se, como relatado por Brei (1996) e Miranda (2018), que não há consenso sobre os significados de corrupção. Ademais, tendo em vista que os resultados de campo se baseiam na percepção dos entrevistados, é de esperar que haja diferenças na interpretação desse fenômeno (Sadek, 2019).

Os resultados da categoria "integridade" estão sintetizados na Tabela 1. Todas as perguntas feitas nessa categoria e na de "estrutura" permitiam respostas múltiplas, por isso os valores percentuais foram calculados sob uma amostragem de 11 entrevistas. 


\section{TABELA 1 RESULTADOS DA CATEGORIA “INTEGRIDADE”}

\begin{tabular}{|c|c|c|c|c|c|c|}
\hline Categoria & Categoria analítica & Indicadores & PADs & PADs (\%) & Entrevistas & Entrevistas (\%) \\
\hline \multirow{12}{*}{ Integridade } & \multirow{7}{*}{$\begin{array}{l}\text { Instrumentos de detecção } \\
\text { das irregularidades }\end{array}$} & Denúncia interna & 18 & $37 \%$ & 11 & $100 \%$ \\
\hline & & Controle externo & 11 & $22 \%$ & 7 & $64 \%$ \\
\hline & & Auditoria interna & 1 & $2 \%$ & 6 & $55 \%$ \\
\hline & & Controle interno & 9 & $18 \%$ & 4 & $36 \%$ \\
\hline & & Denúncia externa & 6 & $12 \%$ & 3 & $27 \%$ \\
\hline & & Corregedoria & - & - & 1 & $9 \%$ \\
\hline & & Outros & 4 & $8 \%$ & 2 & $18 \%$ \\
\hline & \multirow{5}{*}{$\begin{array}{l}\text { Medidas institucionais da } \\
\text { Integridade }\end{array}$} & Controle interno & - & - & 2 & $18 \%$ \\
\hline & & Auditoria Interna & - & - & 10 & $91 \%$ \\
\hline & & Denúncias & - & - & 11 & $100 \%$ \\
\hline & & Promoção da ética & - & - & 11 & $100 \%$ \\
\hline & & Transparência & - & - & 11 & $100 \%$ \\
\hline
\end{tabular}

Fonte: Dados da Pesquisa.

No que concerne aos instrumentos de detecção das irregularidades verificados nos PADs, os mais usados foram os canais internos de denúncia (37\%), seguidos dos mecanismos de controle externo (22\%) e interno (18\%). Esses dados são consoantes com a percepção dos entrevistados, que consideraram a denúncia realizada em canais internos (100\%), os mecanismos de controle externo (64\%) e a auditoria interna (55\%) os canais mais usados para detectar desvios de conduta. Todos os entrevistados revelaram que as Ifes não têm uma unidade administrativa específica de controle interno e que, em geral, os procedimentos de controle são feitos pela auditoria interna e/ou por outros setores da instituição. Tal achado corrobora a análise de Fortini e Shermam (2017) de que diversos entes da administração pública brasileira não contam com unidade responsável pelo controle interno e que, os que contam, ocupam uma posição na estrutura organizacional que revela a pouca importância que lhe é dispensada.

Estudos desenvolvidos na Austrália, na Nova Zelândia e pela ACFE, maior organização antifraude do mundo, também identificaram a denúncia como principal forma de detecção da conduta corrupta (ICAC, 2018; Sardenberg \& Ayres, 2019). No entanto, apesar de o servidor público ter a obrigatoriedade de registrar uma denúncia quando tiver ciência da irregularidade em decorrência de seu trabalho, a pesquisa da ICAC (2018) apurou que 34\% dos que testemunharam alguma má conduta ou irregularidades no local de trabalho, não denunciavam por medo de retaliação. Cumpre destacar que o medo em realizar denúncias também foi expressado por 8 dos entrevistados.

Assim, evidencia-se que a implantação e a divulgação de medidas voltadas à proteção ao denunciante e ao incentivo a denúncias podem contribuir para coibir ações corruptas. Como uma das formas de proteger o denunciante, a ICAC (2018) recomenda que as instituições divulguem sobre a garantia da confidencialidade e a possiblidade de realizar uma denúncia anônima. 
Todos os respondentes relataram que existe uma Comissão de Ética na Ifes em que atuam. No entanto, verificou-se que algumas Ifes têm adotado uma postura ativa, por meio da capacitação dos servidores sobre ética (entrevistados 6 e 9); da divulgação de cartilhas sobre deveres, direitos e proibições dos servidores públicos (entrevistados 7 e 9); e de treinamento dos novos servidores sobre as regras de conduta e normas da organização (entrevistados 4 e 6). Os achados remetem ao estudo empírico desenvolvido por Bonfim e Silva (2019), que demonstraram que a promoção da ética e de regras de conduta contribui para a diminuição de ações desonestas. Portanto, ainda que estabelecer uma relação entre uma postura ativa da Comissão de Ética e a ausência de corrupção seja temerário com base nos achados da pesquisa, ações voltadas ao incentivo da conduta ética dos servidores podem contribuir para a prevenção de atitudes corruptas.

A respeito da transparência, todos os respondentes relataram que as Ifes dispõem de políticas voltadas à promoção dessa medida. No entanto, apenas 2 citaram campanhas no intuito de ampliar a conscientização e estimular os setores a disponibilizar as informações. Desse modo, infere-se que a maioria dos respondentes associa a transparência à disponibilização de informações nas páginas institucionais e às respostas dadas aos cidadãos via e-Sic. Esse achado é consoante com a percepção do entrevistado 2, que revelou que a Ifes em que trabalha apresenta uma "transparência ativa falha e a passiva, perfeita".

Durante a pesquisa documental dos PADs, contudo, apuraram-se fragilidades nos sistemas de acesso à informação, tendo em vista que $18 \%$ das Ifes descumpriram os prazos estabelecidos pela LAI e $47 \%$ indeferiram o pedido. Ainda que, após a interposição dos recursos, tenha havido a concessão de acesso aos processos por parte de $82 \%$ das Ifes, notou-se uma resistência ao fornecimento dessas informações, corroborando Cunha e Antunes (2021) e Mohallen et al. (2018). Depreende-se da pesquisa que, não obstante os avanços alcançados nas últimas décadas, com a criação das leis de acesso à informação e de mecanismos voltados à promoção da transparência pública, é preciso que as Ifes busquem maior efetividade de acesso.

Em relação à categoria "estrutura", de acordo com a percepção dos entrevistados, a principal dificuldade para a prevenção e o combate à corrupção é o corporativismo. Os respondentes relataram que há muita resistência dos servidores a participar das comissões processantes, em razão do receio em julgar os próprios pares. Esses achados são corroborados por Odilla (2020), que demonstrou que, graças ao comportamento de autoproteção dos funcionários públicos, eles não se sentem confortáveis naquele papel, situação consoante com a percepção de alguns entrevistados que informaram que há membros da comissão processante que procrastinam a conclusão de processos, visando à prescrição das penas, e aderente à análise documental da pesquisa, que revelou sanções prescritas nos PADs.

Outro problema relatado pelos respondentes e consoante com análise documental se refere ao despreparo das comissões processantes, que acarreta nulidade dos processos. Esses achados são corroborados pelo estudo de Vieira (2012), que revelou que muitos processos de sindicância ou PADs são anulados pela falta de capacitação e especialização dos profissionais que atuam nas comissões processantes. Tais dados reforçam as dificuldades de servidores para investigar os próprios pares, seja pelas limitações em julgar os colegas, seja pela falta de estrutura, recursos e treinamento para realizar essas diligências. 


\section{CONSIDERAÇÕES FINAIS}

Diante das denúncias de corrupção noticiadas pela mídia nos últimos anos envolvendo Ifes, organizações voltadas à promoção da formação intelectual e cidadã, desenvolveu-se esta pesquisa, junto a todas as 17 Ifes de Minas Gerais, com o objetivo de analisar de que forma o ambiente organizacional se configura no combate à corrupção nesses locais à luz da integridade. Para isso, analisaram-se 49 PADs instaurados nessas instituições de 2015 a 2019 e realizaram-se 11 entrevistas com servidores dessas Ifes, diretamente envolvidos na condução dos PADs.

Os principais achados da pesquisa sugerem que a baixa ocorrência de casos de corrupção nas Ifes parece não estar intrinsecamente ligada à eficiência dos mecanismos de combate à corrupção, tendo em vista os coincidentes relatos dos entrevistados sobre as dificuldades para prevenir e combater esse fenômeno, como postura reativa da ouvidoria e das comissões de integridade e de ética, ausência de unidades de correição, carência de medidas para tratar dos conflitos de interesse, medo dos servidores de realizar denúncias, acúmulo de tarefas, entre outras. Ademais, das 8 medidas institucionais analisadas, apenas 3 - tratamento de denúncia, promoção da ética, transparência e acesso à informação -, ainda que com ressalvas, foram citadas por todos os entrevistados como medidas utilizadas no controle da corrupção nas Ifes em que trabalham. Esses achados corroboram o estudo do TCU (2018), que indicou que 94\% das Ifes de Minas Gerais estão expostas ao risco de fraudes e corrupção, em virtude de fragilidades nos controles.

O estudo sugere que a compreensão do conceito de corrupção influencia a percepção e a análise do fenômeno, bem como que, quando a maioria dos entrevistados relata que não há casos de corrupção nas Ifes ou que há casos esporádicos, isso pode se dar pela percepção de o fenômeno ser comparado com outros de grandes dimensões, como os escândalos corporativos de elevado impacto midiático, tendo em vista que todos os casos analisados nesta pesquisa podem ser classificados como "pequena corrupção" (Miranda, 2018). Contudo, embora todos os tipos de corrupção devam ser firmemente combatidos, os impactos da corrupção sistêmica ("grande corrupção"), nos cenários institucional, político e econômico para o país, são de uma magnitude sem precedentes (Bechara \& Goldschmidt, 2020). Em relação às medidas institucionais de integridade, os achados da pesquisa constataram muitas limitações na implementação delas, o que pode estar ligado ao contingenciamento e a cortes de recursos das Ifes. Todavia, essa discussão perpassa este artigo.

No que concerne às limitações da estrutura referentes ao combate à corrupção, depreende-se do estudo que o corporativismo corresponde ao principal gargalo para o enfrentamento desse fenômeno. Para superar essa limitação, sugere-se uma corregedoria bem estruturada, responsável por instruir e auxiliar nas comissões processantes por meio de apoio técnico, assim como na cobrança para o cumprimento dos prazos. Dessa forma, poderá contribuir para a redução da nulidade processual e da prescrição das penas, bem como para a formação e a capacitação de um banco de dados com membros de distintos setores, de modo a evitar que servidores lotados no mesmo ambiente organizacional que os investigados sejam membros dessas comissões, minimizando as ações de proteção aos pares.

Sugere-se que novos estudos sejam desenvolvidos para verificar a institucionalização das medidas da integridade nas Ifes como estratégia de combate à corrupção. Por fim, considera-se que esta pesquisa ratificou a relevância de estudar um fenômeno presente no cenário brasileiro desde a colonização e que ainda é responsável por sérios danos à sociedade e à educação pública no país. 


\section{REFERÊNCIAS}

Ang, Y. (2020). Unbundling corruption: revisiting six questions on corruption. Global Perspectives, 1(1), 1-19.

Balbe, R. (2006). Uma longa história de corrupção: dos anões às sanguessugas. Revista da CGU, 1(1), 61-76.

Bardin, L. (2016). Análise de conteúdo. São Paulo, SP: Edições 70.

Barreto, F., Midlej, S., \& Gomes, A. (2019). Corrupção no setor público: agenda de pesquisa e principais debates a partir da literatura internacional. Administração Pública e Gestão Social, 11(3), 1-18.

Bataglia, M., \& Farranha, A. (2020). Corrupção, transparência e CGU: analisando o contexto para a implementação do direito de acesso à informação. Revista NAU Social, 10(19), 23-50.

Bechara, F., \& Goldschmidt, P. (2020). Lessons of Operation Car Wash: a legal, institutional, and economic analysis. Washington, DC: Wilson Center. Recuperado de https://direitosp.fgv.br/ sites/direitosp.fgv.br/files/arquivos/bi-09212020car_wash_report_v2.pdf

Bonfim, M., \& Silva, C. (2019). Inhibitory mechanisms on dishonesty of groups and individuals. Journal of Accouting, Management and Governance, 22(2), 205-226.

Brei, Z. (1996). Corrupção: dificuldades para definição e para um consenso. Revista de Administração Pública, 30(1), 64-77.

Bresser-Pereira, L. (2006). Gestão do setor público: estratégia e estrutura para um novo Estado. In L. Bresser-Pereira \& P. Spink (Eds.), Reforma do Estado e administração pública gerencial. Rio de Janeiro, RJ: FGV.

Caetano, E., \& Campos, I. (2019). A autonomia das universidades federais na execução das receitas próprias. Revista Brasileira de Educação, 24, e240043.

Castro, P., Amaral, J., \& Guerreiro, R. (2019). Aderência ao programa de integridade da lei anticorrupção brasileira e implantação de controles internos. Revista de Contabilidade e Finança, 30(80), 186-201.

Cochrane, C. (2020). Teaching integrity in the public sector: Evaluating and reporting anticorruption commissions' education function. Teaching Public Administration, 38(1), 78-94.

Collis, J., \& Hussey, R. (2005). Pesquisa em administração. Porto Alegre, RS: Bookman.

Controladoria-Geral da União. (2020). Painel Correição em Dados. Recuperado de http://paineis. cgu.gov.br/corregedorias/index.htm

Cunha M. C., Filho, \& Antunes, L. F. T. (2021). Regime legal de classificação de informações no Brasil: problemas teóricos, empíricos e (in) compatibilidade com a ordem jurídica democrática. Cadernos EBAPE.BR, 19(1), 138-151.

Decreto $n^{\circ}$ 7.203, de 04 de junho de 2010. (2010). Dispõe sobre a vedação do nepotismo no âmbito da administração pública federal. Brasília, DF. Recuperado de http://www.planalto.gov.br/ ccivil_03/_ato2007-2010/2010/decreto/d7203.htm

Decreto $n^{\circ}$ 7.724, de 16 de maio de 2012. (2012). Regulamenta a Lei $n^{\circ} 12.527$, de 18 de novembro de 2011, que dispõe sobre o acesso a informações previsto no inciso XXXIII do caput do art. $5^{\circ}$, no inciso II do $\$ 3^{\circ}$ do art. 37 e no $\$ 2^{\circ}$ do art. 216 da Constituição. Brasília, DF. Recuperado de http:// www.planalto.gov.br/ccivil_03/_ato2011-2014/2012/ decreto/d7724.htm

Decreto $n^{\circ}$ 9.203, de 22 de novembro de 2017. (2017). Dispõe sobre a política de governança da administração pública federal direta, autárquica e fundacional. Brasília, DF. Recuperado de http:// www.planalto.gov.br/ccivil_03/_ato2015-2018/2017/ decreto/d9203.htm

Denzin, N., \& Lincoln, Y. (2000). Handbook of qualitative research. London, UK: Sage.

Eisenhardt, K. (1989). Building theories from case study research. Academy of Management Review, 14(4), 532-550.

Faria, R. (2015). Scientific misconduct: how organizational culture plays its part. Tijdschrift over Cultuur \& Criminaliteit, 5(1), 38-54.

Filgueiras, F. (2008). Marcos teóricos da corrupção. In L. Avritzer, N. Bignotto, J. Guimarães, \& H. Starling (Org.), Corrupção: ensaios e críticas. Belo Horizonte, MG: UFMG.

Filgueiras, F., \& Aranha, A. (2011). Controle da corrupção e burocracia da linha de frente: regras, 
discricionariedade e reformas no Brasil. Revista de Ciências Sociais, 54(2), 349-387.

Fortini, C., \& Shermam, A. (2017). Governança pública e combate à corrupção: novas perspectivas para o controle da administração pública brasileira. Revista Interesse Público, 19(102), 27-44.

Fortini, C., \& Shermam, A. (2018). Corrupção: causas, perspectivas e a discussão sobre o princípio do bis in idem. Revista de Investigações Constitucionais, 5(2), 91-112.

Fraga, E., \& Motta, L. (2013). A disputa pela voz: conflito e negociação de sentidos na construção de uma telenarrativa jornalística. Líbero, 16(32), 99-110.

Godinho, T. (2011). Contribuições do direito internacional ao combate à corrupção. Revista da Faculdade de Direito da UFMG, (58), 347-386.

Gomes, R. (2014). Responsabilidade administrativa do servidor público na administração pública federal. Prisma Jurídico, 13(1), 193-212.

Gonçalves, V., \& Andrade, D. (2019). A corrupção na perspectiva durkheimiana: um estudo de caso da Operação Lava-Jato. Revista de Administração Pública, 53(2), 271-290.

Huberts, L., \& Graaf, G. (2014). Why it goes wrong: causes of corruption. In L. Huberts (Ed.), The integrity of governance: what it is, what we know, what is done, and where to go. London, UK: Palgrave Macmillan, 144-166.

Independent Commission Against Corruption. (2018). Corruption and integrity in the nsw public sector: an assessment of current trends and events. Sydney, Australia: Autor. Recuperado de https:// apo.org.au/sites/default/files/resource-files/2018-12/ apo-nid208446.pdf

Leher, R. (2019). Autonomia universitária e liberdade acadêmica. Revista Contemporânea de Educação, 14(29), 208-226.

Lei $n^{\circ} 4.878$, de 03 de dezembro de 1965. (1965). Dispõe sôbre o regime jurídico peculiar dos funcionários policiais civis da União e do Distrito Federal. Brasília, DF. Recuperado de http://www. planalto.gov.br/ccivil_03/leis/14878.htm

Lei nº 8.112, de 11 de dezembro de 1990.(1990). Dispõe sobre o regime jurídico dos servidores públicos civis da União, das autarquias e das fundações públicas federais. Brasília, DF. Recuperado de www.planalto. gov.br/ccivil_03/leis/18112cons.htm

Lei $n^{\circ}$ 9.394, de 20 de dezembro de 1996. (1996). Estabelece as diretrizes e bases da educação nacional. Brasília, DF. Recuperado de www.planalto.gov.br/ ccivil_03/leis/19394.htm

Lei $n^{\circ}$ 12.527, de 18 de novembro de 2011. (2011). Regula o acesso a informações previsto no inciso XXXIII do art. $5^{\circ}$, no inciso II do $\$ 3^{\circ}$ do art. 37 e no $\$ 2^{\circ}$ do art. 216 da Constituição Federal; altera a Lei $\mathrm{n}^{\circ}$ 8.112, de 11 de dezembro de 1990; revoga a Lei $\mathrm{n}^{\circ} 11.111$, de 5 de maio de 2005, e dispositivos da Lei no 8.159, de 8 de janeiro de 1991; e dá outras providências. Brasília, DF. Recuperado de www. planalto.gov.br/ccivil_03/_ato2011-2014/2011/lei/ 112527.htm

Lei $n^{\circ}$ 12.813, de 16 de maio de 2013. (2013). Dispõe sobre o conflito de interesses no exercício de cargo ou emprego do Poder Executivo federal e impedimentos posteriores ao exercício do cargo ou emprego; e revoga dispositivos da Lei $n^{\circ} 9.986$, de 18 de julho de 2000, e das Medidas Provisórias nos 2.216-37, de 31 de agosto de 2001, e 2.225-45, de 4 de setembro de 2001. Brasília, DF. Recuperado de http://www. planalto.gov.br/ccivil_03/_ato2011-2014/2013/lei/ 112813.htm

Lei no 12.846, de 01 de agosto de 2013. (2013). Dispõe sobre a responsabilização administrativa e civil de pessoas jurídicas pela prática de atos contra a administração pública, nacional ou estrangeira, e dá outras providências. Brasília, DF. Recuperado de http://www.planalto.gov.br/ccivil_03/_ato20112014/2013/lei/112846.htm

Machado, M., \& Paschoal, B. (2016). Monitorar, investigar, responsabilizar e sancionar: a multiplicidade institucional em casos de corrupção. Novos Estudos Cebrap, 35(1), 11-36.

Marani, S., Brito, M., Souza, G., \& Brito, V. (2018). Os sentidos da pesquisa sobre corrupção. Revista de Administração Pública, 52(4), 712-730.

Marcelino, C., \& Oliveira, S. (2021). Attack, assent or defend? Strategic (political) responses to corruption scandals. Organizações \& Sociedade, 28(96), 187-207.

Mendonça, R., \& Figueiredo, J. (2019). No olho do furacão: protagonismo e incerteza nas Jornadas de Junho de 2013. Revista do Serviço Público, 70(4), 735-754. 
Miranda, L. (2018). Unificando os conceitos de corrupção: uma abordagem através da nova metodologia dos conceitos. Revista Brasileira de Ciência Política, 25, 237-272.

Mohallem, M., Brandão, B., Oliveira, I., France, G., Aranha, A., Martini, M., ... Wanick, L. (2018). Novas medidas contra a corrupção. Rio de Janeiro, RJ: FGV.

Odilla, F. (2020). Oversee and punish: understanding the fight against corruption involving government workers in Brazil. Politics and Governance, 8(2), 140-152.

Oliveira, R., \& Neves, D. (2014). O sistema brasileiro de combate à corrupção e a Lei no ${ }^{\circ}$ 2.846/2013 (Lei Anticorrupção). Revista Brasileira de Direito Público, 12(44), 9-21.

Oliveira, T. (2019). As políticas científicas na era do conhecimento: uma análise de conjuntura sobre o ecossistema científico global. Perspectivas em Ciência da Informação, 24(1), 191-215.

Organização para a Cooperação e o Desenvolvimento Econômico. (2020). Public Integrity Handbook. Paris, France: OCDE. Recuperado de https://read. oecd-ilibrary.org/governance/oecd-public-integrityhandbook_ac8ed8e8-en\#page1

Osipian, A. (2008). Corruption and coercion: university autonomy versus state control. European Education, 40(3), 27-48.

Pinho, J., \& Sacramento, A. (2018). O círculo vicioso da corrupção no Brasil: limites estruturais e perspectivas de rompimento. Revista do Serviço Público, 69, 181-209.

Pinto, C. (2011). A banalidade da corrupção: uma forma de governar o Brasil. Belo Horizonte, MG: Editora UFMG.

Pires, A., \& Oliveira, K. (2020). Fiscalização de contratos: um olhar sob a atuação dos fiscais de contratos de duas universidades federais mineiras. Research, Society and Development, 9(9), e932997714.

Portaria CGU n 57, de 04 de janeiro de 2019. (2019). Altera a Portaria CGU no 1.089 , de 25 de abril de 2018. Brasília, DF. Recuperado de www.in.gov. br/materia/-/asset_publisher/Kujrw0TZC2Mb/ content/id/58029864
Resolução no 510, de 07 de abril de 2016. (2016). Brasília, DF. Recuperado de http://conselho.saude. gov.br/resolucoes/2016/Reso510.pdf

Romeiro, A. (2015). A corrupção na época moderna: conceitos e desafios metodológicos. Revista Tempo, 21(38), 216-237.

Rose-Ackerman, S. (2005, novembro). The challenge of poor governance and corruption. Revista Direito GV, Especial, 207-266.

Rose-Ackerman, S., \& Palifka, B. (2016). Corruption and government: causes, consequences and reform. Cambridge, UK: Cambridge University Press.

Rothstein, B. (2018). Fighting systemic corruption: the indirect strategy. Daedalus, 147(3), 35-49.

Sadek, M. (2019). Combate à corrupção: novos tempos. Revista da CGU, 11(20), 1276-1283.

Salmons, J. (2014). Qualitative online interviews: strategies, design, and skills. Thousand Oaks, CA: Sage.

Santos, L., \& Bronnemann, M. (2013). Desafios da gestão em instituições de ensino superior. Revista Gestão Universitária na América Latina, 6(1), 1-21.

Sardeberg, D., \& Ayres, R. (2019). Whistleblowing: a denúncia como prática ética. Revista da Fundação Dom Cabral, 13(39), 34-40.

Schwarcz, L. (2008). Corrupção no Brasil Império. In L. Avritzer, N. Bignotto, J. Guimarães, \& H. M. M. Starling (Orgs.), Corrupção: ensaios e críticas. Belo Horizonte, MG: Editora UFMG.

Silva, J., Emmendoerfer, M., \& Cunha, N. (2020). Análise documental ilustrada em administração pública: uma Proposta operacional (re)aplicável. Teoria e Prática em Administração, 10(2), 23-41.

Thiry-Cherques, H. (2009). Saturação em pesquisa qualitativa: estimativa empírica de dimensionamento. Revista Brasileira de Pesquisas de Marketing, Opinião e Mídia, 3, 20-27.

Tosta, H., Dalmau, M., Tosta, K., \& Tecchio, E. (2012). Gestores universitários: papel e competências necessárias para o desempenho de suas atividades nas universidades federais. Revista Gestão Universitária na América Latina, 5(2), 1-15.

Transparência Internacional. (2020). Glossário Anticorrupção. Recuperado de https:// transparenciainternacional.org.br 
Tribunal de Contas da União. (2018). Auditoria exposição da administração pública federal: fraude e corrupção. Brasília, DF: Autor. Recuperado de https://meapffc.apps.tcu.gov.br/

Vieira, E., \& Vieira, M. (2004). Funcionalidade burocrática nas universidades federais: conflito em tempos de mudança. Revista de Administração Contemporânea, 37(4), 899-920.
Vieira, J., \& Barreto, R. (2019). Governança, gestão de riscos e integridade. Brasília, DF: Enap.

Viol, D. (2021). Farol da integridade pública: um estudo de caso sobre o programa de integridade da CGU. Revista da CGU, 13(23), 122-141.

Yin, R. (2001). Estudo de caso: planejamento e métodos. Porto Alegre, RS: Bookman.

\section{Jamile Camargos de Oliveira}

https://orcid.org/0000-0002-1602-6198

Mestre em Administração Pública pela Escola de Governo da Fundação João Pinheiro (FJP/MG).

E-mail: jamile_op@hotmail.com

\section{Marcus Vinicius Gonçalves da Cruz}

https://orcid.org/0000-0003-2476-3822

Doutor em Administração pela Universidade Federal de Minas Gerais (UFMG); Pesquisador e professor da Fundação João Pinheiro (FJP/MG). E-mail: marcus.cruz@fjp.mg.gov.br 